\title{
Left main stem coronary artery dissection
}

\author{
PATRICK J MOLLOY, MICHAEL B ABLETT, KENNETH R ANDERSON \\ From the Departments of Cardiac Surgery, Cardiology, and Pathology, Otago Medical School, \\ Dunedin, New Zealand
}

SUMMARY Left main stem coronary artery dissection is a rare cause of sudden death. This occurred in a previously asymptomatic 42-year-old white woman; clinical, arteriographic, and necropsy findings are described. Extrathoracic total body perfusion with isolated catheter perfusion of the dissected coronary artery using cold cardioplegic solution may be effective preoperative treatment.

Spontaneous dissection of the coronary arteries is a rare cause of death occurring predominantly in previously asymptomatic young women, often in the puerperium. ${ }^{1}$ Cases of coronary artery dissection (both acute and delayed) have been recognised in association with coronary angiography; these patients probably have the best chance of survival as the condition can be readily recognised in the catheter laboratory or shortly after the investigation. ${ }^{2}$ It has been described as a complication of cardiac operations, ${ }^{3}$ and related by these authors to postoperative increases of systolic blood pressure or trauma to the coronary orifices by prosthetic valve cages or coronary cannulae. Most cases of coronary artery dissection involve the anterior descending branch of the left coronary artery. Left main stem dissection has been previously described in two cases only. ${ }^{45}$

\section{Case report}

A white woman aged 42 had had four uneventful pregnancies, the last one eight years previously, and gave a history of migraine which had been treated with low dose clonidine (Dixarit). ${ }^{\star}$ She had no recent treatment, was a mild smoker (three a day), and was not taking oral contraceptives. Her husband, a medical practitioner, had noted in the past random blood pressures of 90 to $110 / 65$ to $70 \mathrm{mmHg}$.

At 9.30 am after a leisurely breakfast, she complained of a tight feeling in the chest which rapidly escalated into a severe, crushing retrosternal pain. She became hypotensive, sweaty, and syncopal. She was transferred immediately to Dunedin Hospital where on admission she was conscious, ^Boehringer Ingelheim, PO Box 23-651, Auckland,New Zealand. rational, and anxious. Blood pressure was $90 / 60$ $\mathrm{mmHg}$. An electrocardiogram taken at admission showed an intraventricular conduction defect. On transfer to the medical intensive care unit she developed bradycardia, which responded to atropine, followed by sinus tachycardia. Ventricular fibrillation occurred which was unresponsive to countershock. Cardiac massage was initiated with the Automatic Resuscitator, $f$ maintaining cardiac output, consciousness, and urinary output. Diagnoses considered were pulmonary embolus, myocardial infarction, and aortic dissection.

She was transferred to the catheter laboratory for right and left heart studies while still being mechanically massaged. A systolic pressure of 60 $\mathrm{mmHg}$ was maintained throughout all chambers by the mechanical resuscitator. Pulmonary angiography showed normal pulmonary arteries. For left coronary arteriography resuscitation was temporarily stopped, so that during this time there was no effective cardiac output. After injection (5 s) massage was resumed. Fig. 1 shows the contrast in the left main stem and shows the dissection spreading to the origins of the circumflex and anterior descending branches. No pressure was recorded with the catheter passed through the coronary lumen showing that obstruction was complete. There was no subsequent clearing of the contrast medium.

As there seemed no other prospect of restoring cardiac action, operation was undertaken. Massage continued while femoral vein femoral arterial by-

†M.I.I. Life Aide Cardiopulmonary Resuscitator, Michigan Instruments Inc., 305 W. Fulban Street, Grand Rapids, Michigan 49504, Michigan, USA. 


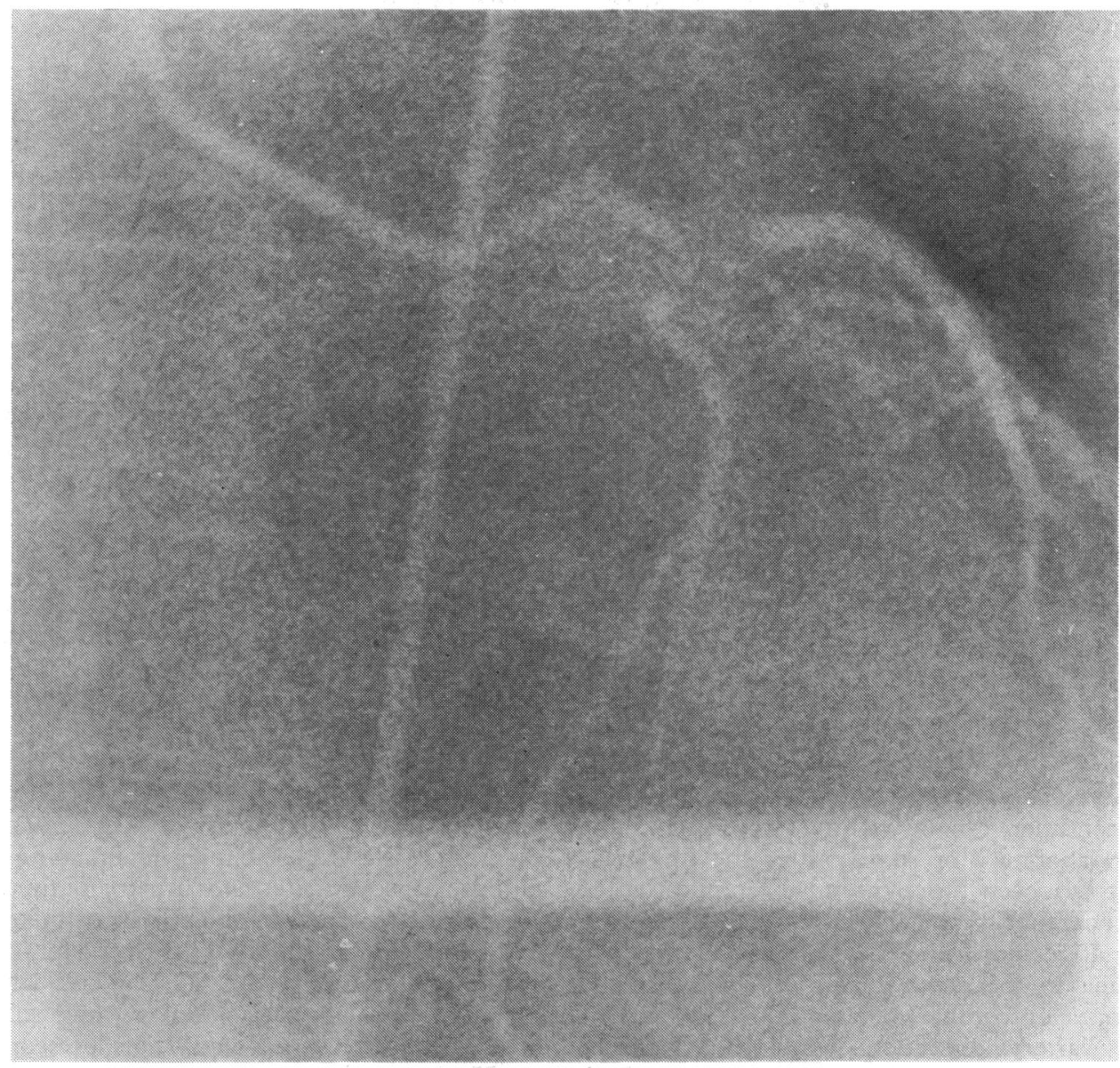

Fig. 1 The left coronary angiogram. Contrast outlines the dissection at the origin of the circumflex and anterior descending arteries. The solid bar is the support of the mechanical resuscitator.

pass was instituted. A flow of 3.3 litres per minute was obtained and hypothermia to $28^{\circ} \mathrm{C}$ was rapidly achieved. The massage was discontinued, the chest rapidly opened, and perfusion converted to bicaval femoral artery bypass. Local cooling with normal saline at $4^{\circ} \mathrm{C}$ was started. The aorta was crossclamped and hypothermic $\left(4^{\circ} \mathrm{C}\right)$ cardioplegic solution ${ }^{\star}$ instilled into the aortic root. On initial inspection the right ventricle was fibrillating and the left ventricle exhibited the 'stone heart' phenomenon. ${ }^{6}$ There was no evidence of dissection on the external surface of the heart. Saphenous

* Composition of aortic root perfusate

Sodium, $157 \mathrm{mmol} / 1$; potassium, $14.2 \mathrm{mmol} / 1$; magnesium, 2.63 $\mathrm{mmol} / 1$; chloride, $99.1 \mathrm{mmol} / 1$; acetate, $23.6 \mathrm{mmol} / 1$; gluconate, $20.1 \mathrm{mmol} / 1$; bicarbonate, $35.0 \mathrm{mmol} / 1$; dextrose, $43.8 \mathrm{~g} / 1$. Osmolality $656 \mathrm{mosmol} / 1$. Isolyte S supplied by: McGaw Laboratories, Glendate, California 91201, USA. vein bypass grafts were attached rapidly to the obtuse marginal and anterior descending coronary arteries. It was noted that a probe in the anterior descending artery readily passed retrogradely into the aorta. The heart defibrillated spontaneously on rewarming but it quickly became obvious that the right ventricle only was contracting. Intra-aortic balloon pumping was instituted but restoration of effective left ventricular contraction was not achieved. It was clear that the ischaemic infarct of the left ventricle had been converted into a haemorrhagic infarct. ${ }^{7}$

\section{PATHOLOGY}

The abnormal findings were confined to the heart which was of normal size $(250 \mathrm{~g})$. The grafts were patent. There was full thickness haemorrhagic 
infarction of the entire free wall of the left ventricle and the anterior third of the ventricular septum. The region infarcted was that supplied by the left coronary artery. The coronary arteries arose normally from the aorta. The main stem of the left coronary artery trifurcated giving rise to a large anterior descending branch, a moderate sized circumflex branch, and a small diagonal branch. An intramural dissection (Fig. 2) involved the left main stem for $1.5 \mathrm{~cm}$, the anterior descending and diagonal branches for a distance of $1 \mathrm{~cm}$ from their origins, and the circumflex for $1.5 \mathrm{~cm}$. A small intimal tear was identified in the left main stem artery near its trifurcation. The dissection extended one-quarter to two-thirds of the circumference of these vessels and was located in the outer media. The false channel contained both clotted and unclotted blood. The right coronary artery was the dominant arterial vessel to the inferior surface of the heart. This artery appeared macroscopically normal with a smooth intimal surface, but histologically there was diffuse intimal thickening, with irregular elastic laminae and abundant smooth muscle cells but without significant fibrosis or lipid deposition. The arterial media contained sparsely scattered pools of mucopolysaccharide material (Fig. 3) which stained positively with alcian blue. These ground substance accumulations were present where the right coronary artery had a muscular media, yet were not observed in the aorta and proximal coronary arteries, both of which had an elastic media. Other small muscular arteries throughout the body were normal. Similar medial pathology was present in the left coronary artery, though this was obscured by the dissection.

\section{Discussion}

This catastrophic cause of sudden death was well described by Malloch $^{1}$ who reviewed 34 published cases. One of these patients may have had a traumatic dissection as there was a history of a kick on the chest by a horse. Their ages ranged from 21 to 62 years (mean of 41.5 years); only four patients were older than 50 . Twenty-six were women, 10 being recently post partum. Only two patients had left main stem dissection; in 27, the dissection involved the anterior descending artery, in four the right coronary artery or its branches, and in one the circumflex artery. ${ }^{4}$ Twenty-four patients died

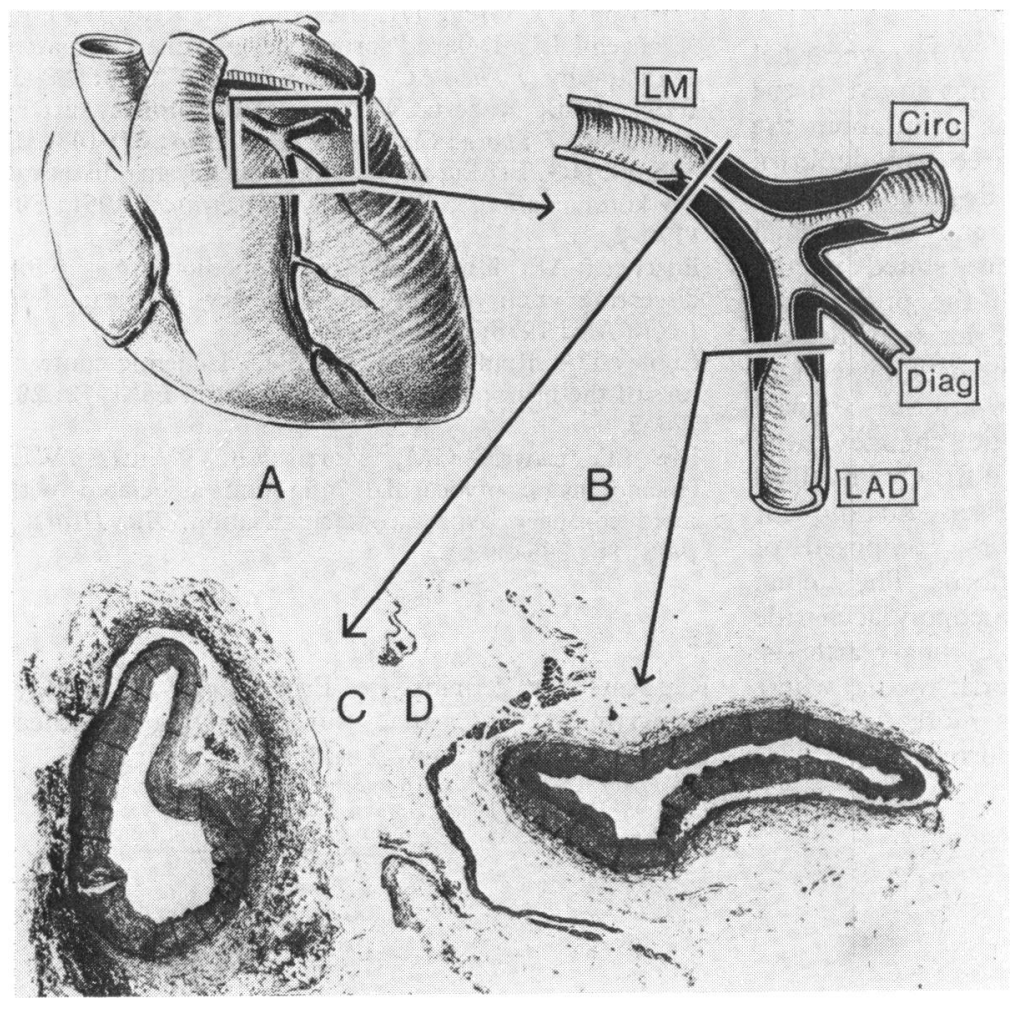

Fig. 2 (A) Diagram of the anterior surface of the heart. (B) Enlarged view of the trifurcation showing the extent of the dissection process in the left coronary artery. (C) and (D) Histological sections of the left main stem coronary artery and anterior descending branch, respectively. The false channel of the left main stem is partially filled with fibrin clot. (Elastic van Gieson. Original magnification $\times 15$ and $\times 25$, respectively.) 


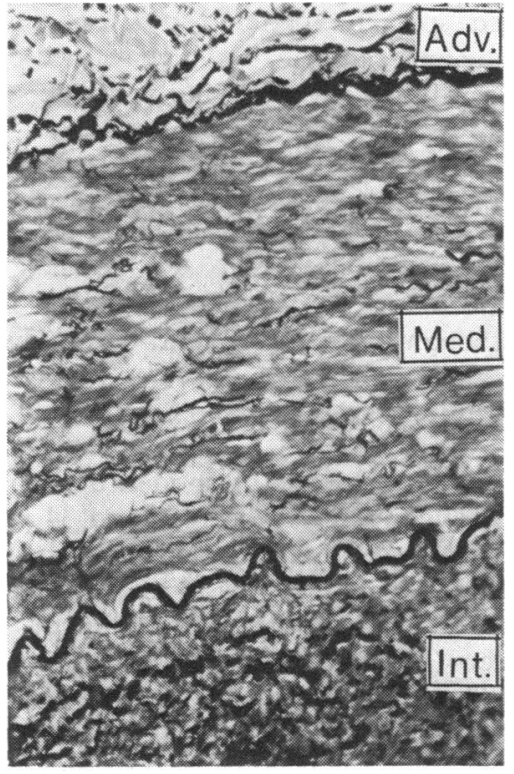

Fig. 3 Histological section of the right coronary artery. Several pools (cysts) of mucopolysaccharide ground substance are present in the arterial media. Moderate musculoelastic intimal thickening is also shown. (Adv., adventitia; Med., media; Int., intima) (Elastic van Gierson. Original magnification $\times 300$.)

suddenly, six patients survived with myocardial infarction, and the outcome was not stated in the other four. Little information was given about the state of the vessels involved: three had doubtful cystic medionecrosis, one medial degeneration, two whorl formation in the media, and two intimal tears, but the histology was not stated in the remainder. The association with the puerperium is unexplained. Hypertension did not seem to be a causative factor as is the case with aortic dissection.

In our patient the coronary arteries showed intimal thickening and mild 'cystic' change in the media. The intimal thickening diffusely involved the proximal portions of both vessels, but did not resemble atherosclerosis and was composed of smooth muscle cells with elastic fibrils. The medial change was characterised by mucopolysaccharide pools ('cysts') and involved both coronary arteries. It is of particular note that the aortic media, where this type of medial pathology is more frequently encountered, was histologically normal.
The diagnosis should be suspected in the young woman with no antecedent history who presents with severe unexpected circulatory collapse especially if the event is related to the puerperium. Because of the rapid course of the catastrophic illness the clinician often has little chance of applying effective treatment. If, however, the diagnosis is suspected, immediate coronary angiography can be performed even if mechanical massage is in progress. Then, if the diagnosis is confirmed, the catheter could be passed beyond the dissection and infusion of hypothermic cardioplegic solution started. Cardiopulmonary bypass can be started via the femoral vein and femoral artery providing organ perfusion before the induction of anaesthesia, while coronary perfusion should protect ischaemic myocardium by substrate provision and hypothermia. The danger of extraluminal penetration exists, but this risk must be accepted in a potentially lethal situation. This approach may offer the patient some hope of survival if such an event occurs in a hospital with cardiac surgical services.

\section{References}

${ }^{1}$ Malloch JA. Dissecting aneurysm of coronary artery. NZ Med F 1974; 79: 914-8.

${ }^{2}$ Harrison LH, Gregg DL, Itescoitz SB, Redwood DR, Michaellis LL. Delayed coronary artery dissection after angiography. $\mathcal{F}$ Thorac Cardiovasc Surg 1975; 69: 880-3. ${ }^{3}$ Bulkley BB, Roberts WC. Isolated coronary artery dissection. F Thorac Cardiovasc Surg 1974; 67: 148-51. ${ }^{4} \mathrm{Schmid}$ HG. Beitrag zin Kenntnis aneurysma dissecans der koronarterien. Schweiz Med Wochenschr 1951; 80: 1170-2.

${ }^{5}$ Boschetti AE, Levine A. Cystic medionecrosis with dissecting aneurysm of the coronary arteries. Arch Intern Med 1978; 102: 562-70.

${ }^{6}$ Cooley DA, Reul G, Wukasch DC. Ischemic contracture of the heart; 'stone heart'. Am f Cardiol 1972; 29: 575-7.

${ }^{7}$ Lie JT, Lawrie GM, Morris GC, Winters WL. Haemorrhagic myocardial infarction associated with aorto coronary bypass revascularisation. Am Heart $\mathcal{f}$ 1978; 96: 295-302.

Requests for reprints to Professor P J Molloy, Department of Cardiac Surgery, Otago Medical School, Dunedin, New Zealand. 